\title{
PENINGKATAN TUNTAS BELAJAR FISIKA MELALUI PEMBELAJARAN FISIKA DENGAN MATERI AJAR BERWAWASAN SETS DAN PENDEKATAN SETS PADA POKOK BAHASAN FLUIDA STATIS DAN DINAMIS KELAS XI-IA SEMESTER 2 SMA NEGERI 2 SEMARANG
}

\author{
Sumarno ${ }^{\text {a.* }}$ \\ ${ }^{a}$ SMA Negeri 2 Semarang \\ Jl Sendangguwo Baru No.1 Semarang 50191, Indonesia \\ Telp/Fax: 6715994/6731778; Email: Sumaryes physic@yahoo.com
}

\begin{abstract}
ABSTRAK
Nilai Ulangan Blok Semester I tahun ajaran 2006-2007 siswa kelas XI IA-3 SMA Negeri 2 Semarang 55\% tidak tuntas belajar Fisika. Hal ini disebabkan karena materi ajar dan pendekatan pembelajaran Fisika kurang menarik perhatian siswa. Untuk meningkatkan jumlah siswa yang mencapai tuntas belajar Fisika diberikan materi ajar Fisika berwawasan SETS dengan pendekatan SETS. Pada siklus I dengan konsep Fluida Statis. Pembagian kelompok merupakan bagian dari pendekatan SETS dibentuk berdasarkan pilihan siswa, dan terbentuk 6 kelompok beranggotakan 7 siswa untuk kelompok 1 sampai 4, sedangkan kelompok 5 dan 6 beranggotakan 8 siswa. Hasil yang dicapai pada siklus I : Aktivitas siswa dalam proses belajar mengajar meningkat, ditandai dengan peningkatan perilaku siswa, dan jumlah siswa yang mencapai tuntas belajar meningkat menjadi $75 \%$. Kelemahan pada siklus I, terletak pada jumlah anggota kelompok terlalu banyak, dan kemampuan akademik kelompok tidak merata.

Pada siklus II dengan konsep Fluida Dinamis, pembagian kelompok yang merupakan bagian dari pendekatan SETS diubah dengan menambah jumlah kelompok menjadi 8 kelompok, kelompok 1 sampai 4 beranggotakan 5 siswa sedangkan kelompok 5 sampai 8 beranggotakan 6 siswa. Pembagian anggota kelompok berdasarkan kemampuan akademik. Dengan mengubah jumlah kelompok dan anggota kelompok pada siklus II ternyata proses belajar mengajar menjadi lebij baik. Dalam menyelesaikan masalah anggota kelompok lebih aktif. Hasil yang dicapai pada siklus II : Aktivitas siswa mengalami peningkatan dari siklus I, jumlah siswa yang mencapai tuntas belajar menjadi $84 \%$.

Dari hasil yang telah dicapai pada siklus I dan siklus II, dapat disimpulkan bahwa materi ajar berwawasan SETS dengan pendekatan SETS dengan pembagian kelompok berdasarkan kemampuan akademik dapat meningkatkan aktivitas belajar siswa dan jumlah siswa yang mencapai tuntas belajar. Materi ajar Fisika berwawasan SETS dan pendekatan SETS dengan pembagian kelompok berdasarkan kemampuan akademik dapat menjadi salah satu model pembelajaran Fisika bagi guru.
\end{abstract}

Kata Kunci: Tuntas Belajar; Wawasan SETS; Pendekatan SETS 


\section{PENDAHULUAN}

Mata pelajaran Fisika di Sekolah Menengah Atas dikembangkan dengan mengacu pada pengembangan fisika yang ditujukan untuk mendidik siswa agar mampu mengmbangkan observasi dan eksperimental serta berfikir atas asas. Hali ini didasari oleh tujuan Fisika yakni mengamati, memahami, dan memanfaatkan gejala-gejala alam yang melibatkan zat (materi) dan energi.

Hasil ulangan blok semester I kelas XI IA-3 SMA Negeri 2 Semarang tahun ajaran 2006-2007 masih jauh dari harapan, yaitu sebagian besar siswa belum tuntas belajar. Untuk kelas XI-IA SMA 2 Semarang tahun ajaran 2006-2007 pada bidang studi Fisika adalah siswa yang dapat mencapai skor minimal 68 untuk suatu kompetensi dasar, atau siswa menguasai $68 \%$ seluruh amteri yang berkatan dengan kompetensi dasar tertentu. Hasil ulangan blok semester I kelas XIIA SMA Negeri 2 Semarang tahun ajaran 2006-2007 untuk bidang studi Fisika adalah sebagai berikut : 55\% memperoleh nilai di bawah 68 dan 45\% siswa tuntas belajar yaitu memperoleh nilai minimal 68. Hasil tes Fisika yang masih rendah ini diduga disebabkan oleh beberapa faktor antara lain : 1) materi ajar yang kurang menarik; 2) fasilitas sarana dan prasarana yang kurang memadai; 3) minat belajar kurang; 4) kurangnya kemampuan guru dalam memilih pendekatan pembelajaran; dan 5) suasana proses belajar mengajar yang kurang kondusif.

Upaya meningkatkan kualitas pendidikan telah banyak dlakukan oleh pemerintah, termasuk berbagai pelatihan bagi guru Fisika di Semarang. Namun demikian masih sedikit informasi mengenai efek pelatihan guru terhadap peningkatan aktivitas siswa dalam proses belajar mengajar. Penelitian ini (Action Research) akan member manfaat pada peningkatan pemahaman konsep-konsep Fisika. Manfaat ini akan secara nyata tercermin pada indikator utama:

1. Pada ulangan harian sekurang-kurangnya $75 \%$ siswa memperoleh nilai minimal 68.

2. Meningkatnya aktivitas siswa dalam proses belajar mengajar Fisika. 
Fokus penelitian ini adalah meningkatkan jumlah siswa yang mencapai tuntas belajar Fisika melalui materi pembelajaran Fisika berwawasan SETS dengan pendekatan SETS. Target peningkatan yang hendak dicapai sekurang-kurangnya 30\% dari kondisi awal pencapaian tuntas belajar yaitu pada semester I yang lalu. Materi pembelajaran Fisika berwawasan SETS adalah suatu materi pembelajaran Fisika yang mengkaitkan konsep sains dengan teknologi dan dampaknya terhadap lingkungan dan masyarakat. Sedangkan yang dimaksud dengan pendekatan SETS adalah suatu kegiatan belajar dengan mengkaitkan materi ajar dengan kehidupan nyata siswa. Kegiatan penelitian dilakukan secara kolaborasi dengan sejawat di SMA Negeri 2 Semarang. Kolaborator setiap periode tertentu melakukan diskusi reflektif untuk meningkatkan validitas pengamatan.

Dari masalah tersebut yang akan dipecahkan adalah "Bagaimanakah materi ajar dan pendekatan pembelajaran yang dapat meningkatkan tuntas belajar Fisika dan aktivitas siswa dalam proses belajar mengajar Fisika?"

\section{METODOLOGI PENELITIAN}

Penelitian dilakukan di SMA Negeri 2 Semarang siswa kelas XI IA-3 berjumlah 44 siswa yang terdiri atas 14 laki-laki dan 30 perempuan. Jumlah siswa yang mendapat nilai minimum 68 kurang dari 75\%, yang memperoleh nilai minimum 68 sebanyak 45\% dan yang memperoleh nilai di bawah 68 sebanyak 55\%. Penelitian dilakukan selama 2 bulan penuh mulai dari bulan Juni sampai dengan pertengahan Juli 2007.

Metode Penelitian. Penelitian ini merupakan penelitian eksperimen, dengan Teknik Pelaksanaaan Penelitian Tindakan Kelas (Classroom Action Research). Penelitian tindakan menurut Rochman Natawidjaya (1996:45) adalah “pengkajian terhadap permasalahan praktis yang bersifat situasional dan kontekstual, yang ditujukan untuk menentukan tindakan yang tepat dalam rangka pemecahan masalah yang dihadapi atau memperbaiki sesuatu". Penelitian tindakan dilakukan secara kolaboratif antara peneliti dengan subjek yang diteliti, melalui 
prosedur penilaian diri. Sebagai bentuk penelitian praktis,maka dalam bidang pendidikan/pembelajaran, penelitian tindakan kelas mengacu kepada apa yang dilakukan guru untuk memperbaiki proses pengajaran yang menjadi tanggung jawabnya, dapat dilakukan baik secara kelompok maupun pribadi.

Rancangan Penelitian. PTK dilakukan dalam dua siklus. Siklus I dengan konsep Fluida Statis. Tindakan pada siklus berikutnya merupakan perbaikan dari siklus I dengan konsep Fluida Dinamis. Alur penelitian tindakan kelas ditunjukkan pada gambar berikut.

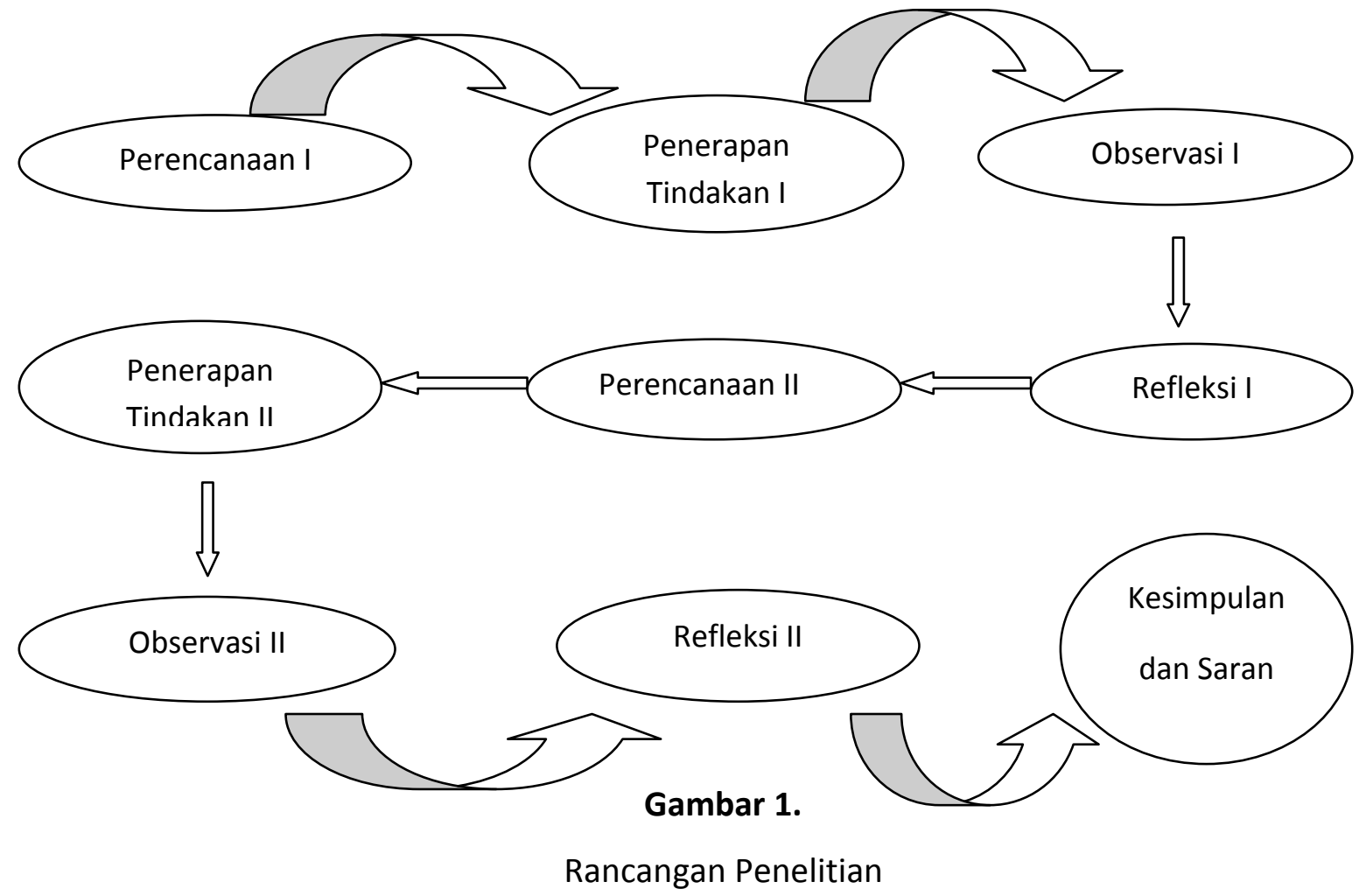

\section{SIKLUS I}

Perencanaan

Perencanaan dalam Classroom Action Research (CAR) meliputi : 1) identifikasi masalah; 2) menyusun rencana pembelajaran disertai work sheet siswa dan evaluasi; 3) intervensi yang digunakan dalam CAR adalah materi pembelajaran berwawasn SETS dengan pendekatan SETS pada konsep Fluida Statis selama 2 minggu yaitu minggu kedua dan keempat bulan Agustus. 
Alat peraga yang digunakan adalah : 1) bejana kecil dan besar menjelaskan tekanan hidrostatis: 2) pipaU menjelaskan hukum hidrostatika; 3) dongkrak hidrolik menjelaskan hukum Pascal; 4) neraca pegas, dua kubus dari besi dan tembaga menjelaskan hukum Archimedes; 5) pipa kapiler mejelaskan kapilaritas; 6) gelas ukur, oli, kelereng, jangka sorong menjelaskan viskositas zat cair.

\section{Penerapan Tindakan}

Kegiatan yang dilakukan meliputi : 1) guru menyediakan alat peraga dan melakukan demonstrasi; 2) siswa mengikuti jalannya demonstrasi; 3) di akhir pertemuan dilakukan diskusi informasidengan siswa dan membuat kesimpulan; 4) Kolaborator berperan mengambil data berupa : a) profil kinerja siswa dan guru, b) wawancara dengan siswa pada akhir pelajaran, c) member angket pada siswa.

\section{Pengumpulan Data}

Data yang dikumpulkan meliputi : 1) data kemajuan hasil belajar yang dipantau dengan ulangan harian; 2) data tentang proses pembelajaran di kelas yang dipantau dengan : a) observasi kelas, b) wawancara dengan siswa, c) data tentang perubahan kinerja guru yang dipantau dengan : (1) observasi kelas dan (2) learning logs guru.

\section{Refleksi}

Data yang diperoleh dari observasi dan hasilbtes belajar siswa akan dianalisis. Kegiatan reflesi antara lain: 1) mengetahui ketuntasan belajar, dengan menganalisis data kuantitatif beupa nilai ulangan harian siswa secara deskriptif, yaitu dicari rata-rata kelas. Jika 75\% siswa telah mencapai nilai 68 berarti siswa kelas XI IA-3 telah mncapai tuntas belajar; 2) data kualitatif yang berupa keaktifan siswa dalam proses belajar mengajar di kelas direkam ditranskripsi dan digolongkan. Menganalisis data kuantitatif lainnya berupa wawancara terhadap siswa; 3) mencari kelemahan dalam penelitian siklus I sebagai dasar penyusunan rencana siklus II. 


\section{SIKLUS II}

\section{Perencanaan Ulang}

Siklus II ini merupakan penyempurnaan siklus I dengan sub pokok bahasan Fluida Dinamis. Intervensi dilakukan selama dua minggu yaitu minggu pertama dan kedua bulan Mei. Alat peraga yang digunakan adalah: 1) selang plastik menjelaskan Hukum Kontinuitas, 2) selang plastic dibentuk leher angsi menjelaskan Hukum Bernoulli, 3) venturimeter menjelaskan penerapan Hukum Bernoulli. Kegiatan yang dilakukan meliputi : a) identifikasi masalah, b) intervensi tindakan, 3) menyusun rencana pembelajaran serta work sheet siswa dan evaluasinya.

\section{Penerapan Tindakan}

Melaksanakan rencana pembelajaran dan work sheet dengan materi berwawasan SETS dan pendekatan SETS. Melakukan perbaikan siklus I serta perbaikan yang dilakukan pada siklus II terhadap siklus I berupa : 1) pengurangan anggota kelompok, 2) pemilihan ulang anggota kelompok berdasarkan kemampuan akademik siswa, 3) optimalisasi alat peraga, menggunakan work sheet siswa yang dilengkapi dengan penjelasan yang jelas dan sistematik.

\section{Pengumpulan Data}

Data yang terpenting meliputi : 1) data tentang kemajuan hasil belajar siswa dipantau dengan ulangan harian atau tes; 2 ) data tentang proses pembelajaran dipantau dengan : a) classroom observer form, b) wawancara dengan siswa, c) pemberian angket pada siswa.

\section{Refleksi}

Refleksi CAR dalam siklus II difokuskan pada pengalaman yang diperoleh siklus sebelumnya dan menilai kembali sasaran perbaikan yang ditetapkan. Bila hasil analisis dan refleksi tidak dapat mengatasi masalah yang dipecahkan pada siklus yang lalu, maka dilakukan perbaikan lebih lanjut dengan membidik secara jeli apa sebenarnya masalah yang muncul. Kegiatan refleksi sama dengan proses pada siklus I. 
Teknik dan pengumpulan data dengan teknik survey melalui wawancara dan angket, teknik test dan teknik dokumentasi. Adapun alat/instrument pengambil data yang digunakan untuk observasi adalah : 1) pedoman wawancara, 2) lembar observasi aktivitas siswa dan guru dalam KBM, 3) seperangkat tes, untuk mengetahui kemajuan hasil belajar, 4) Angket dan 5) catatan lapangan oleh kolaborator.

Validitas tes dilakukan dengan cara : 1) Face validity (anggota AR saling mengecek validitas instrument), dan 2) Content (isi sesuai dengan materi yang diajarkan/sesuai dengan isi kurikulum). Data yang dianalisis terdiri atas data primer yang bersumber dari : 1) observasi, 2) wawancara siswa, dan 3) angket serta data sekunder bersumber dari : 1) daftar nama siswa yang tidak tuntas belajar, 2) daftar nilai ulangan harian, dan 3) buku perkerjaan rumah (PR). Semua data yang ada, baik primer dan sekunder diolah dengan mencari rata-rata setiap nilai test kemudian dijumlah dan dicari rata-rata keseluruhan yang hasilnya disesuaikan dengan indikator belajar tuntas yang diharapkan dalam bentuk prosentase.

\section{Indikator Kinerja}

Pemahaman dan penguasaan konsep Fisika ditunjukkan oleh meningkatnya hasil belajar siswa dan target peningkatan sekurang-kurangnya 30\% dari kondisi awal (sebelum pelaksanaan tindakan). Keberhasilan lain adalah ditunjukkan oleh dua indikator utama yaitu : 1) sekurangkurangnya 75\% siswa kelas XI IA-3 SMA N 2 Semarang mendapat nilai ulangan harian 68, 2) aktivitas siswa dalam PBM meningkat.

\section{HASIL PENELITIAN DAN PEMBAHASAN}

Hasil belajar pada siklus I dengan jumlah peserta ulangan harian 44 siswa yang memperoleh nilai < 68 sebanyak 11 siswa dan yang memperoleh $\geq 68$ sebanyak 33 siswa dengan nilai rata-rata 69,61. Hasil belajar pada siklus II dengan jumlah peserta ulangan harian 44 siswa yang memperoleh nilai <68 sebanyak 7 siswa dan yang memperoleh $\geq 68$ sebanyak 37 siswa dengan nilai rata-rata 71,36 . Tabel berikut ini menyajikan nilai rata-rata kelas dan 
ketuntasan belajar sebelum AR, siklus I dan siklus II.

Tabel 1

Nilai Rata-rata dan Ketuntasan Belajar Sebelum Action Research

\begin{tabular}{|l|c|c|c|}
\hline & $\begin{array}{c}\text { Sebelum AR } \\
\text { (nilai ulangan Blok Semester I) }\end{array}$ & Siklus I & Siklus II \\
\hline Nilai rata-rata kelas & $67,95 \%$ & $69,61 \%$ & $71,36 \%$ \\
\hline Ketuntasan belajar & $45 \%$ & $75 \%$ & $84 \%$ \\
\hline
\end{tabular}

Data aktivitas siswa dan guru diperoleh dari kuesioner melalui peilaku siswa dan guru selama proses PBM. Di bawah ini tabel hasil kuesioner tentang perilaku siswa dan guru sebelum AR, akhir siklus I dan akhir siklus II.

Tabel 2

Perilaku Siswa Sebelum Action Research

\begin{tabular}{|c|c|c|c|c|c|c|c|c|c|c|c|c|c|}
\hline \multirow{2}{*}{ No } & \multirow{3}{*}{ Pertanyaan } & \multicolumn{5}{|c|}{ Sebelum AR } & \multicolumn{5}{c|}{ Siklus I } & \multicolumn{3}{c|}{ Siklus II } \\
\cline { 3 - 15 } & & TP & KD & SR & SL & TP & KD & SR & SL & TP & KD & SR & SL \\
\hline 1 & 27 & 10 & 7 & - & 15 & 15 & 14 & - & 8 & 18 & 18 & - \\
\hline 2 & 32 & 8 & 4 & - & 14 & 14 & 10 & 6 & 8 & 18 & 12 & 8 \\
\hline 3 & 30 & 12 & 2 & - & 16 & 17 & 8 & 3 & 9 & 19 & 10 & 6 \\
\hline 4 & 32 & 10 & 2 & - & 12 & 20 & 8 & 4 & 7 & 22 & 10 & 5 \\
\hline 5 & 34 & 8 & 2 & - & 20 & 12 & 8 & 4 & 10 & 15 & 12 & 7 \\
\hline 6 & 27 & 12 & 5 & - & 15 & 6 & 10 & 3 & 10 & 18 & 12 & 4 \\
\hline 7 & & 22 & 15 & 5 & 2 & 12 & 18 & 9 & 5 & 8 & 20 & 10 & 6 \\
\hline 8 & 33 & 8 & 3 & - & 16 & 18 & 8 & 2 & 7 & 21 & 11 & 5 \\
\hline 9 & 32 & 10 & 2 & - & 15 & 15 & 7 & 7 & 10 & 17 & 9 & 8 \\
\hline 10 & & 28 & 10 & 6 & - & 10 & 18 & 12 & 4 & 6 & 20 & 13 & 5 \\
\hline
\end{tabular}


Tabel 3

Perilaku Guru Sebelum Action Research

\begin{tabular}{|c|c|c|c|c|c|c|c|c|c|c|c|c|c|}
\hline \multirow{2}{*}{ No } & \multirow{3}{*}{ Pertanyaan } & \multicolumn{5}{|c|}{ Sebelum AR } & \multicolumn{4}{c|}{ Siklus I } & \multicolumn{4}{c|}{ Siklus II } \\
\cline { 3 - 14 } & & TP & KD & SR & SL & TP & KD & SR & SL & TP & KD & SR & SL \\
\hline 1 & 32 & 12 & - & - & 10 & 22 & 10 & 2 & 6 & 22 & 14 & 2 \\
\hline 2 & 38 & 4 & 2 & - & 12 & 24 & 6 & 2 & 7 & 25 & 10 & 2 \\
\hline 3 & 36 & 6 & 2 & - & 14 & 16 & 10 & 4 & 8 & 18 & 12 & 6 \\
\hline 4 & 34 & 8 & 2 & - & 15 & 15 & 12 & 2 & 5 & 18 & 14 & 7 \\
\hline 5 & 28 & 14 & 2 & - & 14 & 18 & 8 & 4 & 8 & 20 & 10 & 6 \\
\hline 6 & 32 & 10 & 2 & - & 18 & 15 & 7 & 4 & 8 & 20 & 10 & 6 \\
\hline 7 & 30 & 10 & 4 & - & 18 & 15 & 7 & 4 & 8 & 20 & 10 & 6 \\
\hline 8 & & 32 & 8 & 4 & - & 14 & 14 & 9 & 7 & 8 & 16 & 10 & 10 \\
\hline 9 & & 37 & 5 & 2 & - & 15 & 15 & 10 & 4 & 7 & 18 & 13 & 6 \\
\hline 10 & & 40 & 4 & - & - & 10 & 14 & 15 & 5 & 8 & 15 & 16 & 5 \\
\hline
\end{tabular}

Keterangan : TP = Tidak pernah, KD = Kadang-kadang, $\mathrm{SR}=$ Sering, $\mathrm{SI}=$ Selalu

Dari tabel tersebut di atas penurunan jumlah jawaban "tidak pernah" dari kondisi awal (sebelum AR) dengan akhir siklus I dan akhir siklus pada setiap siswa dan perilaku guru sangat besar sehingga dapat disimpulkan bahwa terjadi peningkatan aktivitas siswa dan guru.

Tabel 4.

Aktivitas Siswa

\begin{tabular}{|c|c|c|c|c|c|c|c|c|c|}
\hline \multirow[t]{2}{*}{$\mathrm{N}$} & \multirow{2}{*}{$\begin{array}{l}\text { Nomor } \\
\text { Perilaku yang diamati }\end{array}$} & \multicolumn{8}{|c|}{$\begin{array}{c}\text { Observasi ke : } \\
\text { (dalam persen (\%)) }\end{array}$} \\
\hline & & 1 & 2 & 3 & 4 & 5 & 6 & 7 & 8 \\
\hline 1 & 1 & 20 & 40 & 50 & 70 & 75 & 80 & 90 & 90 \\
\hline
\end{tabular}




\begin{tabular}{|l|c|c|c|c|c|c|c|c|c|}
\hline 2 & 2 & 25 & 40 & 60 & 75 & 80 & 80 & 90 & 90 \\
\hline 3 & 3 & 30 & 45 & 50 & 60 & 75 & 80 & 85 & 90 \\
\hline 4 & 4 & 40 & 50 & 60 & 80 & 85 & 85 & 90 & 90 \\
\hline 5 & 5 & 15 & 20 & 30 & 50 & 75 & 80 & 90 & 90 \\
\hline 6 & 6 & 20 & 30 & 40 & 50 & 60 & 70 & 80 & 90 \\
\hline 7 & 7 & 25 & 30 & 40 & 50 & 60 & 70 & 75 & 80 \\
\hline 8 & 8 & 10 & 15 & 20 & 25 & 30 & 50 & 70 & 80 \\
\hline 9 & 9 & 15 & 20 & 25 & 30 & 40 & 50 & 70 & 80 \\
\hline 10 & 10 & 20 & 30 & 40 & 50 & 60 & 75 & 80 & 90 \\
\hline
\end{tabular}

Tabel 5

Aktivitas Guru

\begin{tabular}{|c|c|c|c|c|c|c|c|c|c|}
\hline \multirow{2}{*}{ No } & \multirow{7}{*}{$\begin{array}{c}\text { Nomor } \\
\text { Perilaku yang diamati }\end{array}$} & \multicolumn{7}{|c|}{ Observasi ke : } \\
\cline { 2 - 10 } & 11 & 2 & 3 & 4 & 5 & 6 & 7 & 8 \\
\hline 1 & 12 & & 50 & 90 & 90 & 90 & 90 & 90 & 90 \\
\hline 2 & 13 & & 50 & 90 & 90 & 90 & 90 & 90 & 90 \\
\hline 3 & 14 & 50 & 90 & 90 & 90 & 90 & 90 & 90 & 90 \\
\hline 4 & 15 & 50 & 50 & 75 & 75 & 75 & 75 & 75 & 75 \\
\hline 5 & 16 & 90 & 90 & 90 & 90 & 90 & 90 & 90 & 90 \\
\hline 6 & 17 & 90 & 90 & 90 & 90 & 90 & 90 & 90 & 90 \\
\hline 7 & 18 & & 90 & & 90 & & 90 & & 90 \\
\hline 8 & 19 & 90 & 90 & 90 & 90 & 90 & 90 & 90 & 90 \\
\hline 9 & 20 & 90 & 90 & 90 & 90 & 90 & 90 & 90 & 90 \\
\hline 10 & 11 & 90 & 90 & 90 & 90 & 90 & 90 & 90 \\
\hline
\end{tabular}

Berdasarkan tabel tersebut di atas persentase aktivitas guru dari observasi awal (1) sampai observasi akhir (8) meningkat, kondisi ini menunjukkan bahwa aktivitas siswa dan guru 
dalam PBM meningkat.

Wawancara dilakukan tiga tahap; sebelum AR, pada akhir siklus I dan akhir siklus II. Hasilnya menunjukkan bahwa dengan pembelajaran Fisika berwawasan SETS dengan pendekatan SETS membuat siswa menjadi aktif, dan menyukai pelajaran Fisika.

Hipotesis pertama. Ketuntasan belajar Fisika sebesar $75 \%$ pada siklus I sudah mencapai indikator utama penelitian ini yaitu 75\% siswa memperoleh nilai ulangan harian $\geq 68$.

Hipotesis kedua. Ketuntasan belajar Fisika yang dicapai pada siklus II sebesar 84,09\% menunjukkan adanya peningkatan dari siklus I.

\section{KESIMPULAN}

Berdasarkan hasil penelitian tindakan kelas yang telah diuraikan maka dapat diambil suatu kesimpulan sebagai berikut.

1. Pembelajaran Fisika dengan materi ajar berwawasan SETS melalui pendekatan SETS dapat meningkatkan jumlah siswa yang mencapai tuntas belajar Fisika.

2. Pembelajaran Fisika dengan materi ajar berwawasan SETS melalui pendekatan SETS dapat meningkatkan aktivitas siswa dalam PBM.

3. Pembelajaran Fisika dengan materi ajar berwawasan SETS melalui pendekatan SETS dapat meningkatkan aktivitas guru. 


\section{DAFTAR PUSTAKA}

Abimanyu, S. 1995. Penelitian Tindakan Kelas. Semarang : IKIP Semarang Press

Dahar, 1989. Teori-teori Belajar. Jakarta : Gramedia

Binadja. 2000. Hakekat dan Tujuan Pendidikan SETS Dalam Konteks Kehidupan dan Pendidikan

Yang Ada. Seminar Lokakarya Pendidikan SETS Kerjasama antara SEA MEO RECSAM dan UNNES 14-15 Desember 1999.

Natawidjaya, R. 1996. Peningkatan Kualitas Pendidikan. Bandung : Rosdakarya 